\title{
Ecology and hydrodynamic adaptations of the large foraminiferan Discobotellina biperforata (Hemisphaeramminidae)
}

\author{
Henrik Almers ${ }^{1}$, Tomas Cedhagen ${ }^{2, *}$ \\ 'Villavägen 16, S-560 27 Tenhult, Sweden \\ ${ }^{2}$ Department of Ecology and Genetics, Institute of Biological Sciences, University of Aarhus, Ny Munkegade, Building 540 , \\ DK-8000 Aarhus C, Denmark
}

\begin{abstract}
The benthic disc-shaped foraminiferan Discobotellina biperforata (Collins, 1958) occurs in different morphologies: with or without lunules (holes) through the arenaceous test. Water flume experiments on preserved specimens from Moreton Bay in Queensland, Australia, as well as models, indicate that the lunules have a significant hydrodynamic function. They increase the ability of specimens to resist dislodgment and transport by flow. Experimental closure of the lunules resulted in specimens being swept away at lower current velocities. The various morphologies of $D$. biperforata have been suggested by earlier students to result from an alternation of generations. Different generations in foraminiferans are normally detected by studying the nuclei. A histological study on sectioned lunulate and non-lunulate specimens shows that there is no difference between them in nuclear status. This result strongly suggests that they belong to the same generation.
\end{abstract}

KEY WORDS: Foraminifera Hydrodynamic adaptations Testa Ecological morphology Functional morphology

\section{INTRODUCTION}

Discobotellina biperforata Collins, 1958 is a large, disc-shaped foraminiferan. Its test can reach a diameter of $41 \mathrm{~mm}$ and a thickness of $2.1 \mathrm{~mm}$. It is circular to ellipsoidal in outline and consists of sand grains cemented together. Measurements of wall thickness in bisected specimens suggest that the sand grains can be rearranged during growth (Stephenson \& Rees 1965a). The species inhabits 3 different locations along the east coast of Australia; from Moreton Bay off Brisbane, Queensland (type locality), Linden Bank near Cairns, Queensland, where the paratypes were collected, and from off Wooli, New South Wales (Anonymous 1962). It is benthic and found on sand bottoms at depths ranging from 8 to $75 \mathrm{~m}$, often in areas with quite a strong current.

\section{-Addressee for correspondence}

E-mail: cedhagen@pop.bio.aau.dk
Aquarium experiments by Stephenson \& Rees (1965b) showed that the specimens possess pseudopodia up to $10 \mathrm{~mm}$ long radiating from the edge of the test. Their observations of specimens clearing their upper surface of particles indicate the presence of pseudopodia there as well. The reproduction and life cycle of Discobotellina biperforata still remains largely unknown. At present, the only thing known for sure is that it reproduces by budding. Stephenson \& Rees (1965a) postulated a possible form of sexual reproduction: 'Swellings develop in the centre of imperforates, and evidently the protoplasmic contents are discharged, suggesting the possibility of gamete release'. However, this was never proved.

There are 2 main test shapes: the imperforate (nonlunulate), discoidal form, and the biperforate form with a more ellipsoidal outline and 2 lunules, i.e. holes straight through the test. These 2 forms strongly dominate the samples (Stephenson \& Rees 1965a). There are also uniperforates with 1 lunule, multiperforates 
A
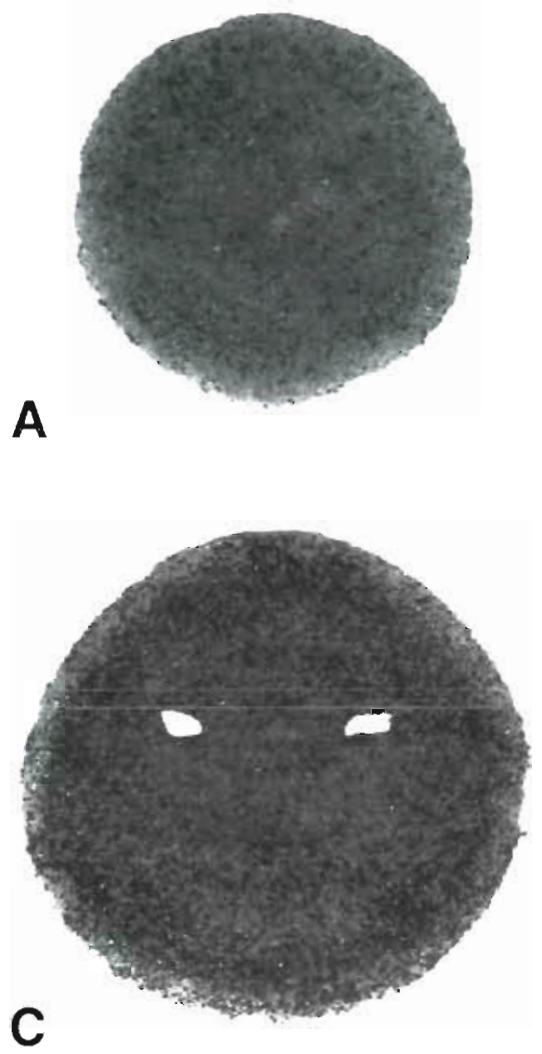

$\mathbf{E}$

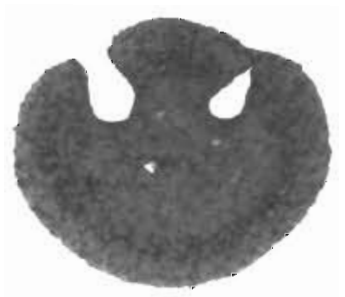

with 3 or more lunules and a crescent shaped form (Fig. 1A-E). Collins (1958) suggested that the different forms could be a result of alternations of generations, leading to the dimorphism described and summarized by, for example, Grell (1973), Boltovskoy \& Wright (1976), Lee (1991) and Lee et al. (1991) among other species of foraminiferans. A common life cycle including dimorphism has a diploid microspheric generation and a haploid megalospheric generation (Lee 1991). Collins' (1958) hypothesis has yet to be proved.

Contrary to Collins, our theory is that the presence of lunules in Discobotellina biperforata is a hydrodynamic adaptation. A lot of species from various phyla have been proved to have structures with similar hydrodynamic functions. A colony of the bryozoan Alcyonidium disciforme Smitt, 1872 has the shape of a convex disc with a central opening. It has been found that this opening, analogous to lunules of sand dollars, has a hydrodynamic function (Kvitek 1989). The keyhole limpet Diodora aspersa (Rathke in Eschscholtz, 1833) has an apical hole in a conical shell. Murdock \& Vogel (1978) found that 'even a slight ambient current increases the rate of water through the mantle cavity about three fold over the still-water pumping rate' This may substantially decrease the fraction of the dissolved oxygen, which the limpets must extract from the water passing through them. Telford (1983) conducted experiments regarding similar features in a wind tun- 
nel and in a water flume with sea urchins of the family Clypeasteroidea, also known as sand dollars. He showed that the lunules of Mellita quinquiesperforata Leske, 1778, the 5-slotted sand dollar, reduce lift and drag: '.. sand dollars derive a real advantage in stability from the lunules'. The critical velocity at which a specimen will be dislodged was higher for the species with lunules than for the ones without. This can be explained by the phenomenon called the Bernouilli principle (Vogel 1981). An object projecting from the bottom affects the passing turbulent flow. The velocity of the flow increases when passing the object, the pressure decreases above it, and a lifting force is thereby created. A water flow through the lunules from the space underneath the test reduces pressure below the object and thereby allows it to stay on the bottom. Thus, the lunules are advantageous to an individual which would suffer if dislodged. We believe that $D$. biperforata has developed lunules for this reason and this constitutes a basis for our investigation.

The first aim of our study was to test the theory of Collins (1958), that the different forms of Discobotellina biperforata result from an alternation of generations. An asexual haploid generation with 1 or a very few large nuclei and a sexual diploid generation with a lot of small nuclei are known from other species of foraminiferans (Lee 1991, Lee et al. 1991). By sectioning imperforate and biperforate specimens we expected to find either equal or different types of nuclei in these 2 different forms. The null hypothesis is that there is no difference between the nuclei of the 2 forms. Our second aim was to determine if the presence or absence of lunula is correlated to the size of the specimen. According to our theories, imperforate specimens should be smaller than lunulates because the effect of the lift increases with test size. We therefore believe that an increased size is correlated to more lunules. Third, we wanted to test if the development of lunules is a hydrodynamic adaptation that reduces lift and drag. The hypothesis is that the critical velocity at which a specimen becomes dislodged is lower for a non-lunulate specimen than for a lunulate one of the same size. If the lunules have no hydrodynamic function, then their closure should not affect the critical velocity. Furthermore, we believe that small specimens have a lower critical velocity than large ones.

\section{MATERIAL AND METHODS}

Field work. All the field work was done by $\mathrm{H}$.A. in Australia between mid and end of March 1994. The specimens were sampled with an epibenthic sledge in Moreton Bay around Shark Spit (27 $15^{\prime} \mathrm{S}, 153^{\circ} 20^{\prime} \mathrm{E}$ ), a sand bank 0.72 to 1.05 nautical miles west of Moreton
Island, at depths of 13 to $27 \mathrm{~m}$, using a sledge with a mesh size of $12 \mathrm{~mm}$. About 500 specimens were collected by dredging, and another 200 by diving. The specimens collected by diving were found on a slope of the sand bank at a depth of 12 to $20 \mathrm{~m}$. Twenty-five specimens were preserved in Bouin for $20 \mathrm{~h}$ and, after being rinsed in tap water, transferred to ethanol (70\%). These specimens were used for the histological sectioning. Formalin (10\%) buffered with borax was used to preserve 510 specimens. Of these, 100 were later removed and dried at normal indoor temperature $\left(20^{\circ} \mathrm{C}\right)$ for $24 \mathrm{~h}$. The dried specimens were used in the hydrodynamic experiments.

Histological study. Five imperforate and 5 biperforate specimens were selected randomly to be sectioned in paraffin. The calcareous grains in the tests were dissolved in a mixture of $9 / 10$ ethanol $(80 \%)$ and $1 / 10$ conc. HCl for $24 \mathrm{~h}$. To dissolve the siliceous sediment particles, a mixture of $1 / 3$ hydrofluoric acid (38\%) and $2 / 3$ distilled water was used for $2 \mathrm{~d}$. This was not efficient enough. The hydrofluoric acid content was increased to $7 / 10$ and the specimens were again incubated for 1 wk. They were then rinsed in distilled water, and rinsed and kept in alcohol (70\%). However, some black ilmenite grains still remained. A pair of forceps was used to remove them from the protoplasm. The protoplasm was embedded in paraffin, sectioned $(7 \mu \mathrm{m})$ and stained with eosin-haematoxylin (Romeis 1968). The staining time in haematoxylin was increased to $45 \mathrm{~min}$, because of the treatment with acid. The slides were mounted by using Canada balsam, and analyzed in an interference contrast microscope.

Size analysis. All specimens, except the ones used in the aquarium observations, were measured and their maximum diameter was recorded. The null hypothesis predicted no difference in size of the various forms and were tested in a fixed 1-factor analysis of variance (ANOVA). A posteriori comparisons of means were performed using the Student-Newman-Keuls test, and homogeneity of variances were tested using Cochran's test.

Hydrodynamic experiment. The experiment was conducted at Kristineberg Marine Biological Research Centre (Sweden). A water flume, constructed according to the description by Vogel (1981), was used (300 cm long, $48 \mathrm{~cm}$ wide). The water depth was $15 \mathrm{~mm}$ to obtain a fully developed boundary layer at the working section and a velocity gradient from the bottom to the surface. The critical velocity at which a model or a specimen was dislodged was determined. It was considered dislodged when, due to lift and drag, it had moved $10 \mathrm{~cm}$ from the original position. To study the effect of lunules (holes), aluminium models of biperforate specimens with 4 different diameters 115 , 25,35 and $50 \mathrm{~mm}$ ) were made. They had a lunule 
diameter of $1.5,2.5,3.0$ and $4.0 \mathrm{~mm}$ respectively. Preserved and dried specimens were also used. The current velocity was measured with a constant-temperature heated-bead thermistor flow meter described by Vogel (1981). Sand with the same particle diameter as the substratum around Shark Spit $(0.3 \mathrm{~mm})$ was glued on a sheet of glass and used as substratum in the water flume. The test results were analyzed as the results from the size analysis.

First the $25 \mathrm{~mm}$ biperforate model was tested with its holes at various angles $\left(90^{\circ}, 180^{\circ}, 270^{\circ}\right.$ and $\left.360^{\circ}\right)$ to the water fluw. This test was done with 10 replicates The aim was to detect the most advantageous direction for a lunulate individual to be sited, i.e. the direction that would give the highest critical velocity. This test was repeated with preserved and dried specimens. In the rest of the experiments, the models as well as the specimens were orientated according to the result of this test. The bipertorate models were then tested with open lunules in the flume. The holes were plugged with Riedel-de Haen stopcock grease to resemble imperforates and the experiment was repeated. By plugging the holes the imperforates and biperforates had an equal diameter and outer shape in the experiment. They also had almost the same mass, since the stopcock grease has a density similar to that of water Every test could therefore be considered a replicate This experiment was repeated 10 times. Hypotheses of the effect of flow on the aluminium models were tested in a 1 -factor ANOVA for differences in orientation, and a 2-factor ANOVA for effects of size and presence/ absence of lunule. All factors were regarded as fixed

Preserved and dried specimens were used in the second part of the experiment. One side of the test of Discobotellina biperforata is convex and the other is concave in many specimens. To find the most stable position for a specimen, the critical velocities of the both sides of 30 individuals were determined. In the next part of the experiment, the specimens were positioned according to this result. The factor tested was morphology: lunulate versus non-lunulate. First, the critical velocities of 50 biperforates with open Iunules were obtained. The lunules were then blocked with the stopcock grease and the test was repeated. The effect of presence/absence of lunule in preserved specimens were tested in a fixed 1 -factor ANOVA.

\section{RESULTS}

\section{Field work}

Contrary to Stephenson \& Rees' (1965b) aquarium observations, we found that the upper side of the specimens in nature was covered with a thin layer of sedi- ment. The only things that were really distinct were the lunules. In the investigated area, Discobotellina biperforata was numerous, but no pattern of distribution was distinguished. Barnacles, identified as $B a i-$ anus trigonus Darwin, 1854, were found growing on many of the specimens (identified by Dr R. T Springthorpe, Australian Museurn).

\section{Histological study}

The main purpose of this study was to identify and compare the size and numbers of the nuclei of sectioned imperforate and biperforate specimens. All specimens examined were multinucleate. The nuclei that frequently occurred in all individuals had oval shapes and sizes of about $90 \mu \mathrm{m}$. The outline of some nuclei was slightly irregular. No differences were found between imperforates and biperforates, and no other forms of nuclei were detected in this investigation (Fig. 2). We have found a structure between the sand grains which we believe cements the grains together (Fig 3). A similar type of structure has been described in other foraminiferans as a mucopolysaccharide (Boltovskoy \& Wright 1976, Bowser \& Bernhard 1993) Intact and fragmentary diatoms, pennate and others, were discovered in a number of the specimens (B. Jönsson pers, comm.). We also found structures that might have been undigested cyanobacteria.

\section{Size analysis}

The diameter of the specimens ranged from $11.1 \mathrm{~mm}$ in the smallest imperforate to $36.4 \mathrm{~mm}$ in a multiperforate specimen. Based upon our collected specimens, the percentage of various morphologies were: imperforates $8.7 \%$ iniperforates $3.9 \%$; biperforates $82.3 \%$; triperforates $3.5 \%$; multiperforates $0.5 \%$; crescent shaped $1.1 \%$. Imperforates are significantly smaller than biperforates $(p<0.05)$ and multiperforates $(p<$ 0.01 ). Uniperforates are significantly smaller than biperforates $(\mathrm{p}<0.05)$ and multiperforates $(\mathrm{p}<0.01)$, (Fig. 4A, Table 1A).

\section{Hydrodynamic experiment}

The orientation of the models gave no significant result, but a similar study of biperforate specimens gave higher critical velocities when the lunules were pointing forwards, away from the flow (Fig. 4B, Table 1B) A significant difference in critical velocity for the models was detected between all different sizes 


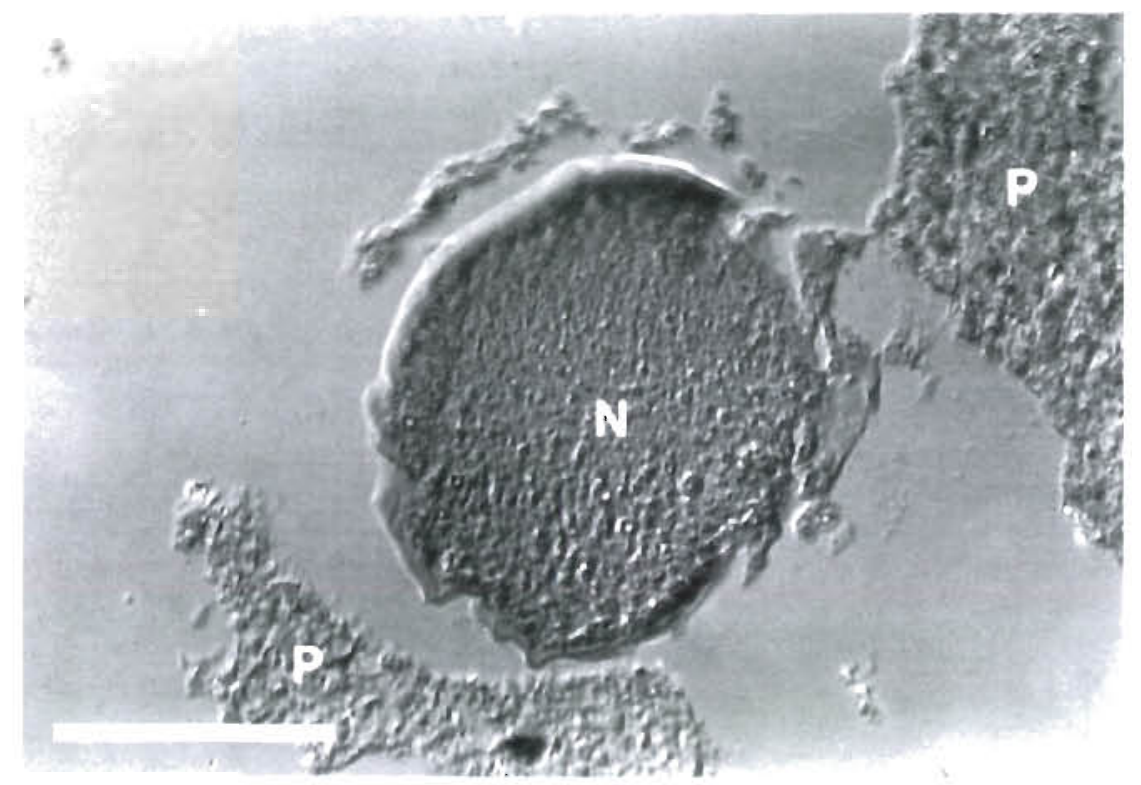

Fig. 2. Discobotellina biperforata. N: nucleus, diameter ca $90 \mu \mathrm{m}$. P: protoplasm. Scale bar $=50 \mu \mathrm{m}$

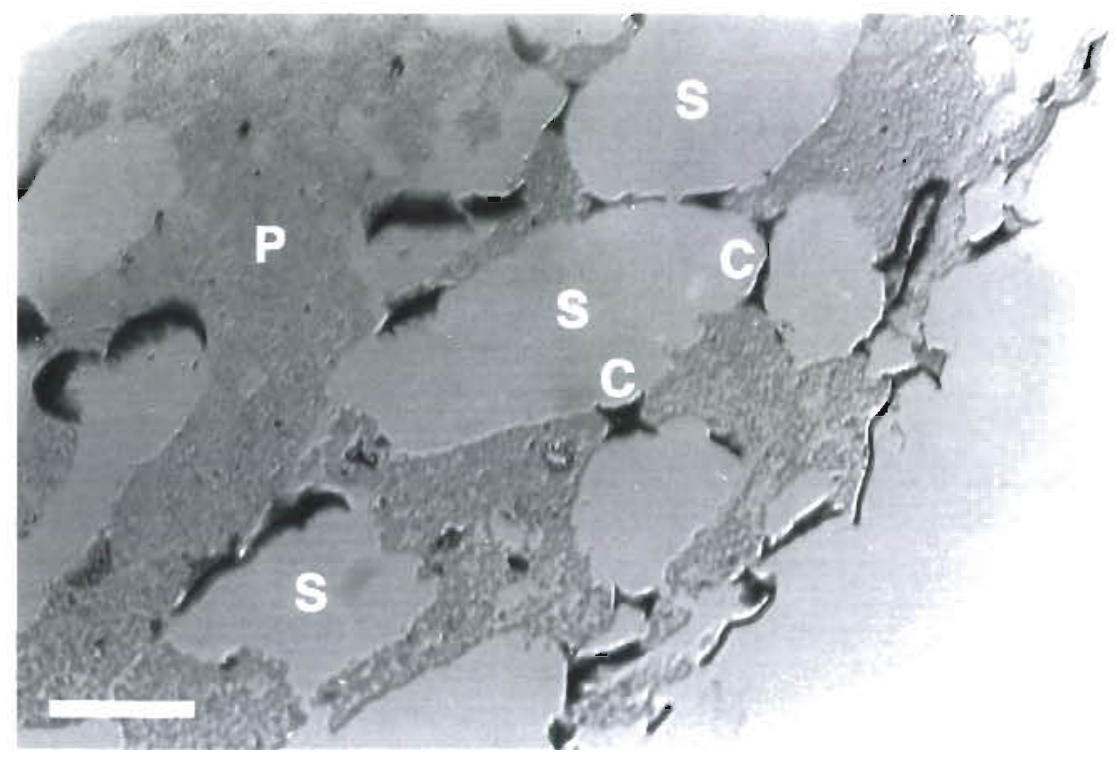

Fig. 3. Discobotellina biperforata. Holes after sand grains (S) were dissolved by acid treatment. Dark structures are interpreted as cement (C). P: protoplasm. Scale bar $=100 \mu \mathrm{m}$

( $p<0.01$ ), i.e. larger models had higher velocities (Fig. 4D). The models with open holes were harder to dislodge than models with blocked holes $(p<0.01)$ (Fig. 4C, Table 1C). The preserved specimens obtained the highest velocities when lying with the concave side downwards $(p<0.01)$ (Fig 4E, Table 1E). Biperforate specimens with open lunules had, like the models with open holes, a higher critical velocity than specimens with blocked lunules ( $p<0.01$ ) (Fig. 4F, Table 1F).

\section{DISCUSSION}

\section{Histological study}

A haploid generation with 1 or a very few large nuclei and a diploid generation with numerous small nuclei are known from other species of foraminiferans (Boltovskoy \& Wright 1976, Lee et al. 1991). It is therefore normally easy to determine the nuclear status by 

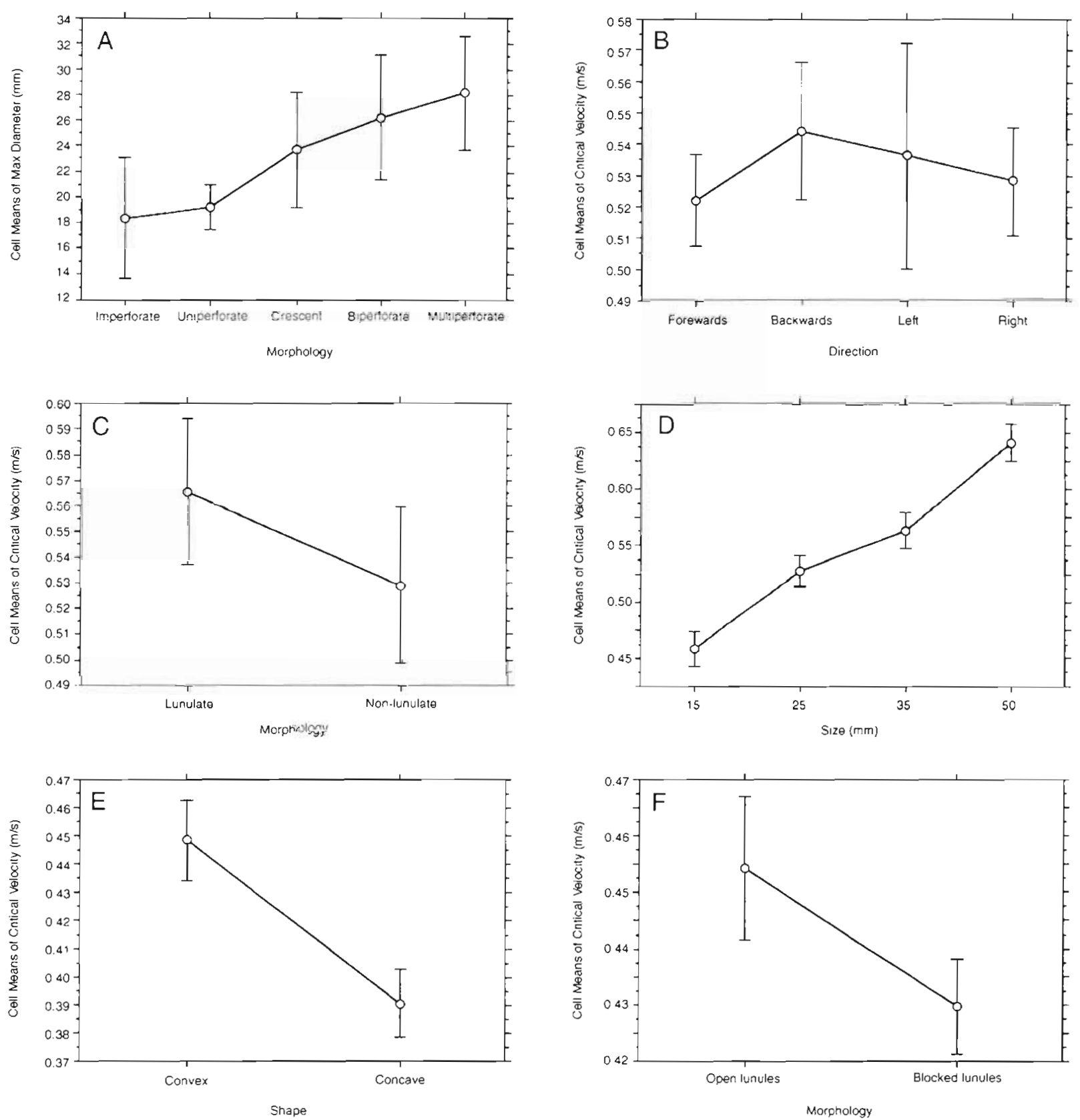

Fig. 4. ANOVA interaction plots. (A) shows that the sizes of the various shapes are significantiy different; (B) shows that models with the lunules directed away from the flow show a tendency to be more stable, but this difference was not significant; (C) shows that the lunulate models were more stable than the non-Iunulate; (D) shows that large models are more stable than small; (E) shows that specimens lying with the convex side upwards are more stable than those with the concave side upwards; (F) shows that specimens with open Iunules are more stable than those with blocked lunules. (A, B) have $95 \%$ confidence error bars. (C-F) have $99 \%$ confidence error bars

studying a sectioned specimen in a light microscope. The result of our study makes it impossible to reject the null hypothesis, which says that there is no difference in nuclear status. Therefore, Collins' (1958) theory has not been proved valid. Consequently, the results strongly suggest that the imperforate and biperforate specimens belong to the same generation. Since only a piece (ca $5 \times 5 \mathrm{~mm}$ ) of the specimens was sectioned, it is impossible to estimate the total number of nuclei per specimen, and it is unlikely that other types of nuclei occur in the remaining parts of the protoplasm. Oval nuclei, sometimes with an irregular outline as in Dis- 
Table 1. ANOVA. Results of the tests corresponding to Fig. 4. Analysis A corresponds to Fig. $4 \mathrm{~A} ; \mathrm{B}$ to Fig. $4 \mathrm{~B} ; \mathrm{C}$ to Fig. $4 \mathrm{C} ; \mathrm{D}$ to Fig. 4D; E to Fig. 4E; and F to Fig. $4 \mathrm{~F}$

\begin{tabular}{|c|c|c|c|c|c|c|}
\hline Analysis & Factor & Dependent & Source & $\mathrm{df}$ & $F$ & $\mathrm{p}$ \\
\hline A: Size & Morphology & Max diameter & Morphology & 4 & 6.86 & 0.0007 \\
\hline B: Models & Direction & Critical velocity & Direction & 3 & 0.83 & 0.4857 \\
\hline C: Models & Morphology and Size & Critıcal velocity & Morphology & 1 & 100.54 & 0.0001 \\
\hline D: Models & Morphology and Size & Critical velocity & Size & 3 & 441.32 & 0.0001 \\
\hline$C+D:$ Models & Morphology and Size & Critical velocity & Morphology $\times$ Size & 3 & 0.27 & 0.8461 \\
\hline E: Preserved & Shape & Critical velocity & Shape & 1 & 73.19 & 0.0001 \\
\hline F: Preserved & Morphology & Critical velocity & Morphology & 1 & 18.57 & 0.0001 \\
\hline
\end{tabular}

cobotellina biperforata, are described in many species of foraminiferans (Føyn 1936, Le Calvez 1953, Nyholm 1953, 1955, 1956, Lengsfeld 1969, Boltovskoy \& Wright 1976. Anderson \& Bé 1978, Bovee 1991).

Stephenson \& Rees (1965a) suggested a rearrangement of the sand grains in the test during growth. We do not share their opinion. The structures that we found between the sand grains (dissolved by acid treatment) in the protoplasm network were differently stained than the rest of the cell material. They were also positioned in a way which proposed that they cement the sand grains together. The 'cement structure' between the sand grains and the circular pattern on the test suggest that rearrangement of sand grains normally does not occur. The cement in Discobotellina biperforata seems to be similar to that found in Astrammina rara by Bowser \& Bernhard (1993) who made a thorough investigation on cement (called bioadhesive) in that species. Additionally, we observed colour patterns in the test surface of $D$. biperforata that are similar to the annual rings of trees. We believe that the consecutive patterns of differently coloured mineral grain originate from an uptake of particles because of marginal growth.

The presence of undigested diatoms in the sectioned species strongly suggests that Discobotellina biperforata feeds on diatoms. It also confirms similar observations by Stephenson \& Rees (1965b).

\section{Epizoans}

A certain species of barnacle frequently lives on Discobotellina biperforata (see Fig. 1F). The species was Balanus trigonus. It was found on $59 \%$ of the specimens. On most of the specimens, the barnacles occurred on the convex side of the test. Small specimens of hydroids were also found growing on the test. Giltay (1934) and Boolootian (1964) have reported that Balanus pacificus Pilsbry, 1916 occurs on Dendraster excentricus (Eschscholtz, 1829), the Pacific sand dollar, which lives in a high-energy environment similar to that of $D$. biperforata. Barnacles were found on all forms and sizes of $D$. biperforata. The fact that the barnacles, with few exceptions, were found only on one side of the test indicates that $D$. biperforata lies on a specific side of the test for a long time.

\section{Size analysis}

According to Telford (1981, 1983, 1988), having lunules would be a perfect adaptation for a large, flat organism which needs to remain on the bottom. The analysis has shown that Discobotellina biperforata combines being large with having lunules. In the size analysis multiperforates were not found to be significantly larger than biperforates. A study on Mellita quinquiesperforata 5 -slotted sand dollar by Alexander \& Ghiould (1980) indicated that the lunules grew more rapidly than the test, i.e. they did not grow allometrically.

According to Stephenson \& Rees (1965a) the crescents develop into biperforate specimens, and should therefore be smaller than biperforates. Our result does not support their theory. The samples of Discobotellina biperforata taken by Stephenson \& Rees (1965a), and by us in 1994, showed that imperforates are normally smaller than individuals with lunules. Telford (1983) found that small sand dollars have a lower critical velocity for being dislodged than larger ones. According to his result the imperforate specimens would have more need for lunules than the large lunulate individuals if they are to remain on the bottom.

\section{Hydrodynamic experiment}

The results of the experiment suggest a significant hydrodynamic function for the lunules of the models and the preserved specimens of Discobotellina biperforata. The comparison of preserved specimens with open and blocked lunules gave a $6 \%$ higher critical velocity for open lunules. In the similar experiment on 
Mellita quinquiesperforata by Telford (1983) a difference of $1.5 \%$ was detected. Specimens lying on their concave side with the lunules pointing away from the flow had the highest critical velocity in our study. This is of course only applicable for preserved specimens orientated in a flow that does not change directions. In Moreton Bay, $D$. biperforata is exposed to tidal currents that change directions, and would have to turn to achieve the most advantageous position if the current has the same velocity in both directions. That would certainly be possible for a specimen by using the pseudopodia.

Both Alcyonidium disciforme and Diodora aspersa (see 'Introduction') inhabit the same type of highenergy areas as Discobotellina biperforata and have similar morphologies. Kvitek (1989) proposed 3 criteria for an unattached, immobile or weakly motile epifaunal species living in high-energy, sedimentary habitats: (1) to maintain proper feeding orientation, (2) avoid being lifted and transported away by current flow or by wave action, and (3) avoid burial. It seems to us that $D$. biperforata has fulfilled all these criteria and we believe that it has evolved a lunulate form, which permits it to remain mostly in the boundary layer at the substratum or slightly buried in a high-energy environment.

Acknowledgements. We are very grateful to the following persons for their support and criticism during our work: Dr Per Jonsson; Mr Mats Lindegarth, M.Sc.; Dr Benno Jonsson; Mr Christoffer Schander, M.Sc.; Ms Petra Lundgren, B.Sc.; Mr Örjan Karlsson; the other colleagues at Tjärno Marine Biological Laboratory; Dr th Svane at Kristineberg Marine Biological. Research Centre (Sweden), for allowing us to use his water flume; Dr Tore Mörnsjö, Biological Institute, University of Göteborg; Mr Hans Frimansson, B.Sc., Mr Mathias Larsson, B.Sc., Mr Torbjörn Åkesson, M.Sc., and Ake and Gun Almers (Sweden); Ms Juliet McGrath, B.Sc.; Ms Petra Ringeltaube, M.Sc.; Professor Jack Greenwood; Dr Ian Tibbetts; Mr Owen Kelly; Mr Michael Porritt, B.Sc., at the University of Queensland for the help during the field work; Dr R. T Springthorpe at the Australian M1useum, for the holp with identifying the barnacles. Dr Andrew Gooday, Southampton, kindly commented on a late version of this manuscript.

\section{LITERATURE CITED}

Alexander DE, Ghiould J (1980) The functional significance of the lunules in the sand dollar, Mellita quinquiesperforata. Biol Bull Mar Biol Lab Woods Hole 1.59:561-570

Anderson OR, Bé AWH (1978) Recent advances in foraminiferal fine structure research. in: Hedley $\mathrm{RH}_{\text {, }}$ Adams CG (eds) Foraminifera, Vol 3. Academic Press, London, p 121-202

Anonymous (1962) Mermaid's penmes. Aust Nat Hist 14(3).87

Boltovskoy E, Wright R (1976) Recent foraminifera. Dr W Junk, The Hague

Boolootian RA (1964) The occurrence of Balanus concavus on the test of Dendraster excentricus. Bull South Calif Acad Sci 63:185-191.
Bovee EC (1991) Sarcodina. In: Harrison FW, Corliss JO (eds) Microscopic anatomy of invertebrates, Vol 1. Protozoa. Wiley-Liss, New York, p 161-259

Bowser SS, Bernhard JM (1993) Structure, bioadhesive distr1bution and elastic properties of the agglutinated test of Astrammina rara (Protozoa: Foraminiferida). J Eukaryot Microbiol 40(2):121-131

Collins AC (1958\} Foraminifera. Great Barrikr Rcef Fxpedition 1928-29. Scient Rep Brit Mus (Nat 1 list) 6(6):335-437

Foyn B (1936) Über die Kernverhältnısse der Foramınifere Myxotheca arenilega Schaudinn. Arch Protistenkd 87: $272-295$

Giltay L (1934) Note sur l'association de Balanus concavus pacificus Pilsbry (Cirripede) et Dendraster excentricus (Eschscholtz) (Echinoderme). Bull Mus R Hist Nat Belg 10: $1-7$

Grell KG (1973) Protozoology. Springer-Verlag. Herdelberg

Kvitek RG (1989) Hydrodynamic morphology and behaviour of a free-living sediment-dwelling bryozoan, Alcyonidium disciforme (Smitt). J Exp Mar Biol Ecol 125:13-32

Le Calvez J (1953) Ordre des Foraminiferes. In: Grassé PP (ed) Traité de zoologie, Tome I. Masson, Paris, p 149-265

Lee JJ (1991) Phylum Granuloreticulosa (Foraminifera). In: Margulis L, Corliss JO, Melkonian M, Chapman DJ (eds) Handbook of Protoctista. Jones and Bartlett, Boston, p $524-548$

Lee JJ, Faber WW, Anderson OR, Pawlowski J (1991) Lifecycles of foraminifera. In: Lee JJ, Anderson OR (eds) Biology of Foraminifera. Academic Press, London, p 285-334

Lengsfeld AM (1969) Nahrungsaufnahme und Verdauung bei der Foraminifere Allogromia laticollaris. Helgoländer Wiss Meeresunters 19:385-400

Murdock GR, Vogel S (1978) Hydrodynamic induction of water flow through a keyhole limpet (Gastropoda, Fissurellidael. Comp Biochem Physiol 61A:227-231

Nyholm KG (1953) Studies on recent Allogromiidae (2): Nemogullmia Iongevariabilis $n$. gen. $n$. sp. from the Gullmar fjord Contr Cushman Found Foramin Res 4:105-106

Nyholm KG (1955) Studies on recent Allogromiidae (4): Phainogullmia aurata n. gen. n. sp. Zool Bidr Uppsala 30 : $465-474$

Nyholm KG (1956) On the life cycle and cytology of the foraminiferan Nemogullmia longevariabilis. Zool Bidr Uppsala 31:483-495

Romeis B (1968) Mikroskopische Technik. R. Oldenbourg Verlag, Wien

Stephenson W, Rees M (1965a) Ecological and life history studies upon a large foraminferan (Discobotellina biperforata, Collins, 1958) from Moreton Bay, Queensland; I. The life cycle and nature of the test. University of Queensland Papers, Department of Zoology. St. Lucia 2:207-223

Strphenson W, Rees M (1965b) Ecological and hfe history studies upon a large foraminiferan (Discobotellina biperforata, Collins, 1958) from Moreton Bay, Queensland; II. Aquarium observations. University of Queensland Papers, Department of Zoolocyy. St. Lucia 2:239-255

Telford M (1981) A hydrodynamic interpretation of sand dollar morphology. Bull Mar Sci 31:605-622

Telford M (1983) An experimental analysis of Iunule function in the sand dollar Mellita quinquiesperforata. Mar Biol 76 : $125-134$

Telford $\backslash$ (1988) Ontogenetic regulatory mechanısms and evolution of mellitid lunules (Echnoidea, Clypeasteroidea). Paleoblology 14(1):52-63

Vogel S (1981) Life in moving fluids. Whllard Grant Press, Boston 